\title{
Childhood Tuberculosis: Current Scenario in India
}

\author{
Gedam DS ${ }^{1}$, Patel $\mathbf{U}^{2}$ \\ Dr D Sharad Gedam, Professor of Pediatrics, Dr Umesh Patel, Associate Professor of Pediaatrics. Both are affiliated with L N \\ Medical College, Bhopal, India \& member of Editorial board.
}

Address for correspondence: Dr Umesh Patel, Email: drumeshpatel@gmail.com

\begin{abstract}
Almost one third of Indian population is having tubercular infection. Children always get infection from open cases of Tuberculosis. Associated malnutrition further increases intensity of tuberculosis. In this editorial we have discussed about current scenario of tuberculosis in India with special emphasis on children.
\end{abstract}

Key words: Tuberculosis in children, prevalence, Tuberculosis.

\section{Introduction}

"Measurement is the first step that leads to control and eventually to improvement. If you can't measure something, you can't understand it. If you can't understand it, you can't control it. If you can't control it, you can't improve it." - H. James Harrington.

What James Harrington said is very relevant to childhood $\mathrm{TB}$ and in particular, to those children under five years who are in close contact with an adult who has been recently diagnosed with active pulmonary TB. Tuberculosis (TB) is one of the most ancient diseases of mankind. It is considered greatest killer of mankind [1]. $\mathrm{TB}$ is now among the 10 major causes of mortality in children [2, 3]. Children with TB infection today represent the reservoir of $\mathrm{TB}$ disease tomorrow. Childhood TB has historically been neglected by the global TB community and the health community and never consider major public health problem. As children with TB are usually less infectious than adults, they have received little attention from national TB control programmes. Even when children are diagnosed with TB and treated for it, many are not registered with or reported to/by national TB programme. The actual burden of pediatric TB is not known but has been assumed that $10 \%$ of total TB load is found in children. Globally, about 1 million cases of pediatric TB are estimated to occur every year accounting for $10-15 \%$ of all $\mathrm{TB}$; with more than 100,000 estimated deaths every year $[3,4]$. A September 2010 paper in the Infectious Disease Clinics of North America journal states why childhood TB should be taken seriously [5]. "Pediatric $\mathrm{TB}$ can be regarded as an emerging epidemic in areas where the adult epidemic remains out of control and Mycobacterium tuberculosis transmission is ongoing. A 2009 study published in the

Pediatric Review: International Journal of Pediatric Research
International Journal of Tuberculosis and Lung Diseases by V.V. Banu Rekha et al. from the Chennai-based National Institute for Research in Tuberculosis (formerly TRC) found that only 14 per cent of child contacts were screened and only 19 per cent were initiated on isoniazid preventive therapy![6].

According to World Health Organization (WHO), TB is a worldwide pandemic. It is a leading cause of death among HIV-infected people. In 2011, the first year when WHO included the estimates of pediatric TB in its annual report, the incidence among children was about half-a-million and the number of children killed was 64,000 . WHO estimates that the annual global burden of TB in children, in 2012 was approximately 530,000 cases (or 6\% of global TB burden), and that up to 74000 children died from TB that year [7]. It is important to note that TBrelated deaths in children infected with HIV are not included in these estimates because they are classified as deaths caused by HIV (i.e. not TB) [7]. These estimates have further limitations, and the burden of TB in children is likely to be higher. There is no data on the burden of multidrug-resistant (MDR-TB) in children. The prevention, diagnosis and management of MDR-TB in children provide special challenges for TB programme and is often only accessible at referral levels of care. So actual burden of TB in children is very likely to be much higher, given the fact that diagnosing childhood TB is a big challenge. Of all the countries that report their TB statistics to WHO, there are 22 countries that are referred to as the TB "high burden" countries (India is one of them) and they have been prioritized at a global level since 2000. These countries accounted for $82 \%$ of all estimated cases of TB worldwide in 2011. Even today in India, two deaths occurs every three minutes from tuberculosis [9]. HIV not only makes diagnosis of TB

Available online at: $\underline{\text { www.pediatricreview.in }} \quad 1$ | P a g e 


\section{Editorial}

more difficult in children, but increases the risk of contracting TB disease 20-40 times [10]. Children differ from adults TB as children much more likely to develop extra-pulmonary TB, as many as $25 \%$ of childhood TB cases are extra-pulmonary cases, compared with $16 \%$ in adults. Children are also more likely to develop other severe forms of TB including disseminated TB and TB meningitis. But the lack of an accurate "gold standard" diagnostic test for $\mathrm{TB}$ in young children is major challenge, and adds to the potential for both an underdiagnosis and an over-diagnosis of cases. A misplaced faith in the protective efficacy of the bacille CalmetteGuérin (BCG) vaccine (although the BCG vaccine has been shown to prevent about $60 \%$ to $90 \%$ of cases of meningeal TB and disseminated TB in young children) and lack of research and investment again make difficult to tackle childhood tuberculosis properly. Major challenges to control TB in India include poor primary health-care infrastructure in rural areas of many states; unregulated private health care leading to widespread irrational use of first-line and second-line anti-TB drugs; spreading HIV infection; lack of political will; and, above all, corrupt administration [9]. Recently scenario is gradually start changing. Contrary to traditional national TB programmes, pediatric tuberculosis has always been accorded high priority by RNTCP since the inception of the programme. In order to simplify the management of pediatric TB, RNTCP in association with Indian Academy of Paediatrics (IAP) has described criteria for suspecting TB among children, has separate algorithms for diagnosing pulmonary $\mathrm{TB}$ and peripheral $\mathrm{TB}$ lymphadenitis and a strategy for treatment and monitoring patients who are on treatment $[11,12]$.Today India's DOTS program is the fastest expanding and the largest programme in the world in the term of patients initiated on treatment and second largest, in terms of population coverage [13].

If the global goal of eliminating TB, initiated by WHO with its "STOP TB" strategy, by 2050 is to be met, treatment and prevention of TB in children needs as much attention as in adults. Unfortunately, BCG, has limited efficacy against the most common forms of childhood TB and its effect is of limited duration. However, screening of household contacts of adult TB patients and provision of preventive drugs to young children must receive higher priority. The time has come to shift our focus from patient-centric care to family-centric care. As India moves towards universal access to prevention, diagnosis and treatment of TB, the little ones amongst us must not be forgotten.

\section{References}

1. Rubin SA. Tuberculosis. Captain of all these men of death. Radiol Clin North Am. 1995 Jul;33(4):619-39.

2. Mathers CD, Boerma T, Fat DM. Global and Regional causes of death. Br Med Bull (2009) 92 (1): 7-32.

3. Swaminathan S, Rekha B. Pediatric Tuberculosis: Global Overview and Challenge. Clin Infect Dis. (2010) 50 (Supplement 3): S184-S194

4. Global tuberculosis control-epidemiology, strategy, financing. WHO Report 2009.

5. Marais B.J. ,Schaaf H.S. Childhood tuberculosis: An emerging and previously neglected problem (Review). Infectious Disease Clinics of North America. 2010 Sep; 24(3):727-49.

6. Banu Rekha, VV, Jagarajamma $K$, Wares $F$, Chandrasekaran $V$, Swaminathan $S$. Contact screening and chemoprophylaxis in India's Revised Tuberculosis Control Programme: a situational analysis. Int J Tuberc Lung Dis.2009 Dec;13(12):1507-12.

7. World Health Organization. WHO. Global Tuberculosis Report.2012. Geneva, Switzerland:WHO;2012.p.100.

8. Marais BJ, Graham SM, Cotton MF, Beyers N. Diagnostic and management challenges for childhood tuberculosis in the era of HIV. J Infect dis 2007;196 Suppl(Suppl 1):S76-85.

9. Gursimrat K Sandhu. Tuberculosis: Current Situation, Challenges and Overview of its Control Programs in India. J Glob Infect Dis. 2011 Apr-Jun; 3(2): 143-150.

10. World Health Organization. Monograph on integrated monitoring of TB/HIV- A case study in Malavi. Geneva:WHO;2009.

11. Kumar A, Gupta D, Nagaraja SB, Singh V, Sethi GR, Prasad J. Updated National Guidelines for Pediatric Tuberculosis in India,2012. Indian Pediatr 2013;50:30106.

12. Mukherjee A, Lodha R, Kabra SK. Changing trends in childhood tuberculosis. Indian journal of pediatrics. 2011;78(3):328-33.

13. Sandhu GK. Tuberculosis: Current situation , challenges and Overview of its Control Program in India.

J Glob Infect Dis. 2011 Apr-Jun;3(2):143-150

\section{How to cite this article?}

Gedam DS, Patel U, Childhood Tuberculosis: Current Scenario in India. Pediatr Rev: Int J Pediatr Res 2014;1(1):1-2. doi: 10.17511/ijpr.2014.i01.01 